\title{
Circadian patterns of plasma cortisol, 17-hydroxyprogesterone, and testosterone in congenital adrenal hyperplasia
}

\author{
H FRISCH, K PARTH, EDITH SCHOBER, AND W SWOBODA \\ Department of Paediatrics, University of Vienna School of Medicine, and Ludwig Boltzman Institut für klinische \\ Endokrinologie und Nuklearmedizin, Vienna, Austria
}

SUMMARY In 11 children aged between 2 and 17 years with (nonsalt-losing) congenital adrenal hyperplasia (21-hydroxylase deficiency) blood was drawn at 90-minute intervals during a 24-hour period and levels of 17-hydroxyprogesterone, testosterone, and cortisol were measured. Levels of 17-ketosteroids and pregnanetriol were measured too in 24-hour urine samples. These measurements were taken under different regimens of treatment and after interruption of treatment. Cortisol levels rose and fell rapidly after administered corticosteroid, and reached unphysiologically high levels. Testosterone levels showed pronounced variations but stayed in the normal range for most of the time even in untreated patients; thus testosterone provides a poor control parameter. Levels of 17-hydroxyprogesterone showed extreme fluctuations and very high peak levels in untreated patients; standard treatment with two or three daily doses of corticosteroids did not prevent a pronounced rise in its level after midnight. After the first morning dose of hydrocortisone a very steep fall was observed. The 24-hour pregnanetriol excretion correlated well with the corresponding total integrated 17-hydroxyprogesterone area. It is concluded that single 17-hydroxyprogesterone values are unlikely to give adequate information about the quality of treatment.

In patients with congenital adrenal hyperplasia control of glucocorticoid substitution therapy is governed by clinical parameters (growth velocity, bone age, pubertal stage) together with biochemical data on 17-ketosteroids (17-KS) and pregnanetriol. Recent advances have drawn attention to the plasma levels of cortisol precursors, especially of 17hydroxyprogesterone (17-OHP), ${ }^{1}$ the value of monitoring this steroid in the management of congenital adrenal hyperplasia having been investigated $^{2-9}$ and found to be limited by the well-known circadian rhythm. ${ }^{10}$ The effect of the time lag between ingesting the drug and blood sampling has not been fully studied, and the same applies to the circadian rhythm. Information on plasma levels of cortisol under substitution therapy is also lacking. Therefore we have studied the circadian patterns of cortisol, 17-OHP, and testosterone under glucocorticoid therapy, and in addition, using the urinary parameters of $17-\mathrm{KS}$ and pregnanetriol, we have assessed the usefulness of single 17-OHP values in the monitoring of treatment.

Patients and methods

In 9 girls and 2 boys aged between $2 \frac{3}{4}$ and $16 \frac{1}{2}$ years under treatment for congenital adrenal hyperplasia due to 21-hydroxylase-deficiency, blood was drawn at 90-minute intervals during a 24-hour period to determine the levels of 17-OHP, cortisol, and testosterone. Levels of 17-KS and pregnanetriol were measured in the corresponding 24-hour urine samples. Three patients (Cases $8,10,11)$ were also studied after stopping treatment for 3 days; one newly diagnosed boy (Case 9) was studied before treatment began and then 2 weeks later. Informed consent for the investigation was obtained from the parents.

Clinical data are shown in Table 1. Glucocorticoids (hydrocortisone or prednisone) were given three times daily at 0800,1230 , and 1830 hours, or twice at 0800 and 1830. Seven patients were treated with hydrocortisone in a mean dose of $19 \cdot 1 \mathrm{mg} / \mathrm{m}^{2}$, and 4 patients received prednisone in a mean dose of $8.8 \mathrm{mg} / \mathrm{m}^{2}$. Two girls (Cases 2 and 6) were given larger prednisone doses but only temporarily.

Details of the methods used are shown in Table 2.

Antisera against 17-hydroxyprogesterone-3-oximeBSA and cortisol-21-succinate-BSA were supplied by Endocrine Sciences, antiserum against testosterone3-oxime-BSA by New England Nuclear. Crossreaction of cortisol antibody with prednisone was 
Table 1 Clinical data of 11 patients with congenital adrenal hyperplasia

\begin{tabular}{|c|c|c|c|c|c|}
\hline \multirow[t]{2}{*}{ Case } & \multirow[t]{2}{*}{ Sex } & \multirow{2}{*}{$\begin{array}{l}\text { Treatment and dose } \\
\left(\mathrm{mg} / \mathrm{m}^{2}\right)\end{array}$} & \multicolumn{2}{|c|}{ Age at admission (years) } & \multirow{2}{*}{$\begin{array}{l}\text { Pubertal } \\
\text { staget }\end{array}$} \\
\hline & & & Chronological & Bone age & \\
\hline 1 & $\mathbf{F}$ & $\begin{array}{l}\text { Prednisone } 5 \cdot 1 \\
(2 \cdot 5 / 5)^{*}\end{array}$ & $10 \cdot 6$ & $15 \cdot 6$ & IV \\
\hline 2 & $\mathbf{F}$ & $\begin{array}{l}\text { Prednisone } 14.4 \\
(5 / 5 / 10)\end{array}$ & $16 \cdot 7$ & 16 & IV \\
\hline 3 & $\mathbf{F}$ & $\begin{array}{l}\text { Prednisone } 5 \cdot 2 \\
(5 / 2 \cdot 5)\end{array}$ & $15 \cdot 6$ & $17 \cdot 6$ & $\mathbf{v}$ \\
\hline 4 & $\mathbf{M}$ & $\begin{array}{l}\text { Hydrocortisone } 16 \cdot 3 \\
(5 / 10)\end{array}$ & $7 \cdot 1$ & 6 & $\mathbf{I}$ \\
\hline 5 & $\mathbf{F}$ & $\begin{array}{l}\text { Hydrocortisone } 26.6 \\
(10 / 10 / 5)\end{array}$ & 7 & $8 \cdot 6$ & I \\
\hline 6 & $\mathbf{F}$ & $\begin{array}{l}\text { Prednisone } 10.6 \\
(5 / 5)\end{array}$ & $6 \cdot 4$ & 11 & III \\
\hline 7 & $\mathbf{F}$ & $\begin{array}{l}\text { Hydrocortisone } 17 \cdot 8 \\
(10 / 20)\end{array}$ & $13 \cdot 6$ & 13 & III \\
\hline 8 & $\mathbf{F}$ & $\begin{array}{l}\text { Hydrocortisone } 16 \\
(8 / 4 / 4)\end{array}$ & $8 \cdot 1$ & 8 & I \\
\hline 9 & $\mathbf{M}$ & $\begin{array}{l}\text { Hydrocortisone } 27 \cdot 2 \\
(10 / 10 / 5)\end{array}$ & $2 \cdot 9$ & 9 & III \\
\hline 10 & $\mathbf{F}$ & $\begin{array}{l}\text { Hydrocortisone } 25.4 \\
(15 / 10 / 5)\end{array}$ & $9 \cdot 6$ & 11 & II \\
\hline 11 & $\mathbf{F}$ & $\begin{array}{l}\text { Hydrocortisone } 14.7 \\
(7.5 / 5 / 2.5)\end{array}$ & $8 \cdot 2$ & 8 & I \\
\hline
\end{tabular}

*Single dose each day. †Tanner's scale.

Table 2 Flowsheet of the radioimmunoassay methods

$1 \mathrm{ml}$ plasma (samples, blanks, quality control pools) $\downarrow$

add $\sim 1500$ counts $/ \min \left[1,2-^{3} \mathrm{H}\right]$ hydrocortisone

add $\sim 1500$ counts/min $\left[1,2{ }^{3} \mathrm{H}\right]$ testosterone to one half of samples

add $\sim 1500$ counts/min $\left[1,2-^{3} \mathrm{H}\right] 17$-hydroxyprogesterone

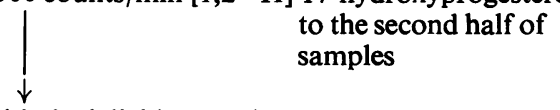

extract with $6 \mathrm{ml}$ dichloromethane

$\downarrow$

take to dryness, redissolve in cyclohexane-benzenemethanol $(60: 40: 10)$

chromatography on sephadex LH 20 minicolumns, elute with cyclohexanebenzene-methanol

$3 \mathrm{ml}$ discard

$$
\downarrow
$$

$3 \mathrm{ml}$ (testosterone and 17-hydroxyprogesterone) dry down, redissolve in $1 \mathrm{ml}$ ethanol, take $1 / 10$ for recovery and suitable aliquots for radioimmunoassays

$9 \mathrm{ml}$ discard

$9 \mathrm{ml}$ (hydrocortisone) dry down, redissolve in $1 \mathrm{ml}$ ethanol, take $1 / 10$ for recovery and suitable aliquots for radioimmunoassay nearly complete; in patients being treated with prednisone therefore, the data for cortisol represent the sum of drug and endogenous cortisol.

Levels of 17-KS were determined spectrophotometrically, and those of pregnanetriol by gas chromatography, using standard laboratory methods.
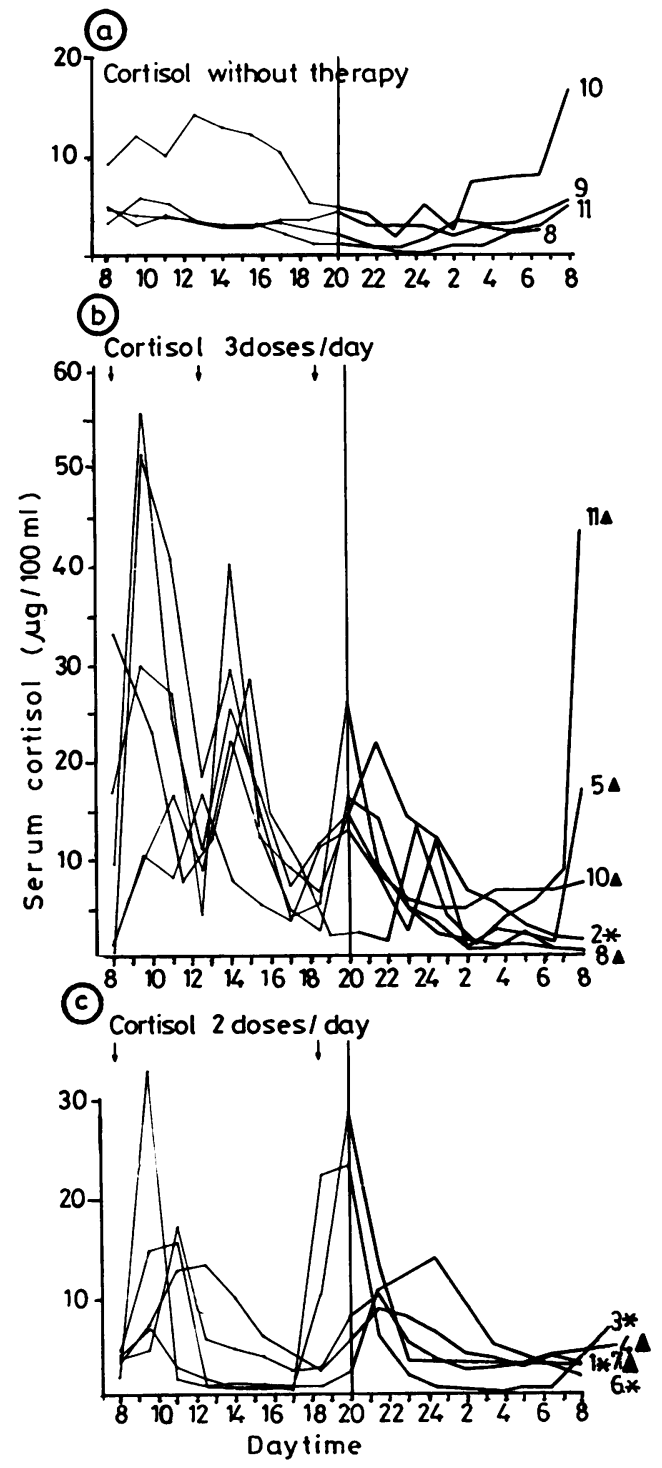

$\Delta$ Hydrocortisone, ${ }^{*}$ prednisone

Fig. 1 Serum levels of cortisol in 11 patients with congenital adrenal hyperplasia (a) without treatment, (b) with 3 doses, and (c) with 2 doses of corticosteroids daily. 


\section{Results}

Fig. 1 shows the diurnal variation of plasma cortisol (or sum of prednisone and cortisol) in children without and with treatment. After glucocorticoid intake there was a rapid rise of plasma levels, the peak values (sometimes unphysiologically high) clearly reflecting the dose. Fall-off was very steep too, especially with hydrocortisone, and after midnight very low levels persisted. In children not on treatment, a weak circadian rhythm still existed. In one girl (Case 10) we found cortisol fluctuation almost normal after the drug had been stopped for 3 days.

Fig. 2 shows the corresponding 17-OHP values. Pronounced fluctuations, extremely high morning and relatively low evening values, characterise the condition without (or before) treatment. Generally, high morning levels were rapidly reduced by the first dose (at 0800 hours). They remained fairly low throughout the day irrespective of the mode of drug application. A steep rise occurred generally during the night between 2300 and 0330 hours. This rise took place later in patients who were given a larger hydrocortisone dose in the evening, and in patients being treated with predisone. Only in the 2 patients who received an increased predisone dose for clinical reasons were the 17-OHP levels low throughout the entire 24-hour period.

The circadian pattern of plasma testosterone is shown in Fig. 3. Considerable fluctuations were noted, especially in untreated patients. Under glucocorticoid treatment the daytime levels were low, and a rapid increase was seen after midnight or earlier, with peak values in the morning.

In Table 3 the 24-hour integrated 17-OHP areas are summarised, the relative fractions of integrated 17-OHP areas for two 12-hour periods (1200-2400 and 2400-1200), integrated testosterone areas, and the corresponding urinary values of $17-\mathrm{KS}$ and pregnanetriol are shown. The integrated areas represent the area between abscissa and the respective steroid curves as shown in the corresponding figures. Correlation between the 24-hour integrated 17-OHP areas and the urinary pregnanetriol $(r=0.79$, $\mathbf{P}<0.01$ ) was good. In order to demonstrate the difference in suppression at different periods of the day, the total integrated area was divided into two 12-hour periods-that is $1200-2400$ and 2400-1200. Under such conditions the 1200-2400 period was much lower than the $2400-1200$ period, and there was no correlation in either period with pregnanetriol ( $r=0.22$ and $r=0.37$ respectively). This observation was made in all treated patients except the 2 children with very high prednisone doses.

Integrated testosterone areas correlated well with urinary 17-KS $(\mathrm{r}=0.88, \mathrm{P}<0.01)$ and correlation of 17-KS and pregnanetriol was also satisfactory, as we had expected $(\mathrm{r}=0.86, \mathrm{P}<0.01)$. Testosterone areas were not divided into two 12-hour periods, because this would have been of no benefit in this study.

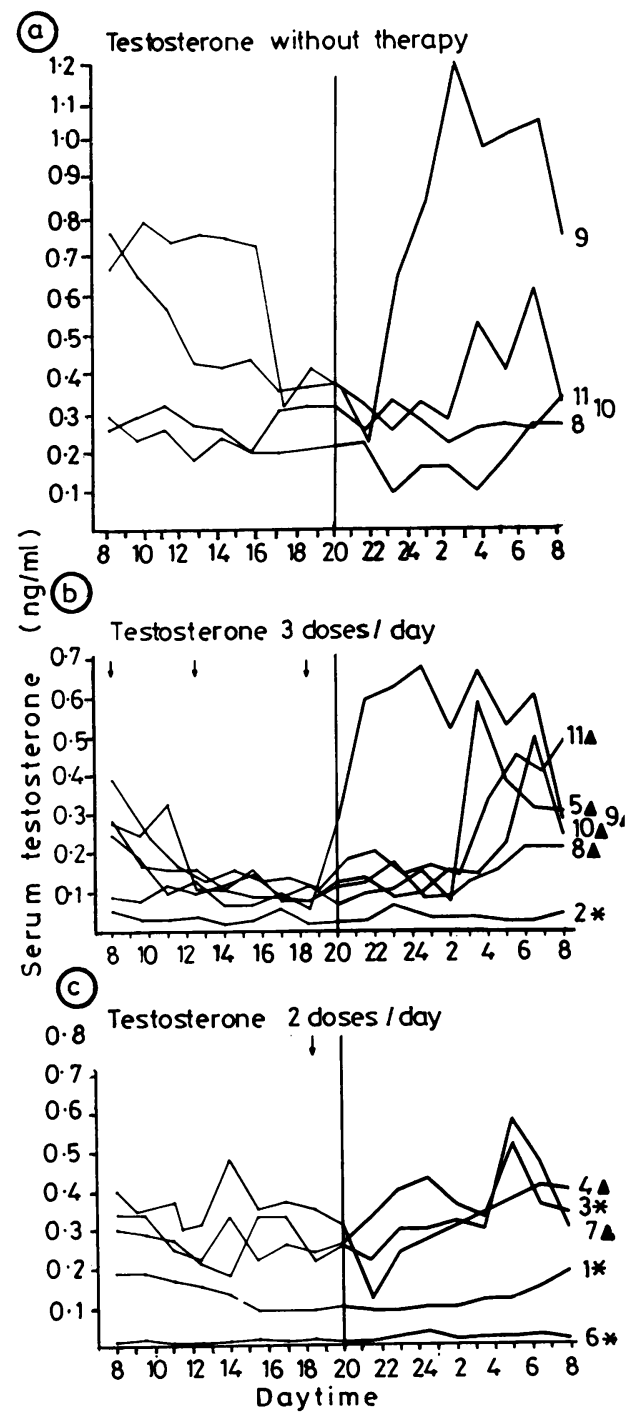

$\Delta$ Hydrocortisone, *prednisone

Fig. 3 Serum levels of testosterone in 11 patients with congenital adrenal hyperplasia (a) without treatment, $(b)$ with 3 doses, and $(c)$ with 2 doses of corticosteroids daily. 
Table 3 Integrated areas of 17-hydroxyprogesterone and testosterone in the serum, and corresponding levels of 17-ketosteroids and pregnanetriol in 24-hour urine samples in 11 children with congenital adrenal hyperplasia

\begin{tabular}{|c|c|c|c|c|c|c|c|}
\hline \multirow[t]{2}{*}{ Case } & & \multirow{2}{*}{$\begin{array}{l}\text { 17-OHP } \\
\text { (nmol/lper } \\
24 \mathrm{~h})\end{array}$} & \multicolumn{2}{|c|}{ Fractions (\%) } & \multirow{2}{*}{$\begin{array}{l}\text { Testosterone } \\
(\text { nmollllper } \\
24 h)\end{array}$} & \multirow{2}{*}{$\begin{array}{l}17-K S \\
(\mu \mathrm{mol} / 24 \mathrm{~h})\end{array}$} & \multirow{2}{*}{$\begin{array}{l}\text { Pregnanetriol } \\
(\mu \mathrm{mol} / 24 \mathrm{~h})\end{array}$} \\
\hline & & & $\begin{array}{l}1200-2400 \\
\text { hours }\end{array}$ & $\begin{array}{l}2400-1200 \\
\text { hours }\end{array}$ & & & \\
\hline \multicolumn{8}{|c|}{ On treatment } \\
\hline 1 & Current therapy & $290 \cdot 5$ & 15 & 85 & $10 \cdot 1$ & $12 \cdot 5$ & 13.4 \\
\hline $2^{*}$ & Current therapy & $56 \cdot 5$ & 47 & 53 & $3 \cdot 1$ & $11 \cdot 1$ & 0.3 \\
\hline 3 & Current therapy & 9695.4 & 20 & 80 & $27 \cdot 0$ & 37.8 & 22.9 \\
\hline 4 & Current therapy & - & - & - & - & 23.6 & 6.5 \\
\hline 5 & Current therapy & $2058 \cdot 5$ & 4 & 96 & 15.9 & $5 \cdot 2$ & 3.6 \\
\hline $6^{*}$ & Current therapy & $41 \cdot 3$ & 49 & 51 & 1.4 & 1.7 & 0.3 \\
\hline 7 & Current therapy & $910 \cdot 5$ & 22 & 78 & 25.7 & - & - \\
\hline \multirow[t]{2}{*}{8} & Under treatment & 2135.9 & 35 & 65 & 10.4 & 9.0 & 9.5 \\
\hline & 4 days without treatment & $6840 \cdot 0$ & 35 & 65 & $17 \cdot 0$ & $21 \cdot 5$ & $27 \cdot 6$ \\
\hline \multirow[t]{2}{*}{9} & Before treatment & $6716 \cdot 1$ & 24 & 76 & $60 \cdot 7$ & $106 \cdot 4$ & $51 \cdot 7$ \\
\hline & After 2 weeks of treatment & $2633 \cdot 2$ & 4 & 96 & $28 \cdot 8$ & $29 \cdot 5$ & $6 \cdot 5$ \\
\hline \multirow[t]{3}{*}{10} & 3 days without treatment & $6097 \cdot 3$ & 21 & 79 & $36 \cdot 4$ & $64 \cdot 8$ & $36 \cdot 0$ \\
\hline & $\begin{array}{l}\text { Treatment for days } 6 \\
\text { after interruption }\end{array}$ & $2605 \cdot 1$ & 5 & 95 & 14.9 & $40 \cdot 6$ & 21.7 \\
\hline & Treatment for 3 months & - & - & - & - & $24 \cdot 6$ & 14.9 \\
\hline \multirow[t]{6}{*}{11} & 3 days without treatment & $11272 \cdot 2$ & 46 & 54 & 23.9 & $76 \cdot 6$ & 63.6 \\
\hline & Treatment for 3 days & & & & & & \\
\hline & after interruption & $3776 \cdot 8$ & 9 & 91 & $22 \cdot 5$ & $37 \cdot 8$ & $44 \cdot 3$ \\
\hline & Treatment for 3 months & - & - & - & - & $19 \cdot 1$ & $5 \cdot 9$ \\
\hline & & & 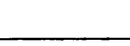 & $\ldots$ & \multicolumn{3}{|c|}{$\smile^{\longrightarrow} r=0,88 \longrightarrow r=0,86$} \\
\hline & & & & . & $r=0,22-r=0$, & & \\
\hline
\end{tabular}

* Patients with increased doses.

Conversion: SI to traditional units-17-OHP: $1 \mathrm{nmol} / 1 \approx 33 \mathrm{ng} / 100 \mathrm{ml}$; testosterone: $1 \mathrm{nmol} / 1 \approx 0.288 \mathrm{ng} / \mathrm{ml} ; 17-\mathrm{KS}: 1 \mu \mathrm{mol} / 24 \mathrm{~h} \approx 0.288$ $\mathrm{mg} / 24 \mathrm{~h}$; pregnanetriol: $1 \mu \mathrm{mol} / 24 \mathrm{~h} \approx 0.336 \mathrm{mg} / 24 \mathrm{~h}$.

\section{Discussion}

In the group of treated patients, blood levels of total glucocorticoids consisting of endogenous and exogenous corticosteroids clearly reflected the time of administration and the quantity of the corticosteroid. Rise and fall were very steep (within 1-2 hours) and a single dose of 10 or $15 \mathrm{mg}$ hydrocortisone led to an unphysiologically high peak value of short duration. The effect of the last dose at 1830 hours persisted only until about midnight, as measured by the suppression of 17-OHP and testosterone levels. In children with interrupted treatment, less pronounced circadian changes and subnormal values were found. The unexpected result in Case 10 of an almost normal circadian cortisol rhythm can be interpreted as agreeing with the clinical findings of a weak enzymatic defect in this late diagnosed case (at age $5 \frac{1}{2}$ years).

Testosterone levels in treated patients were not above the upper limits of normal, with the exception of one boy (Case 9) during the night. From our data the usefulness of testosterone for monitoring treatment ${ }^{6}{ }^{11-13}$ seems slight. In view of the considerable diurnal fluctuations of testosterone shown in this study, a single determination cannot provide adequate information about the quality of treatment.

Extreme fluctuations and very high peak values of 17-OHP in untreated patients with congenital adrenal hyperplasia have been reported. ${ }^{1014}$ Under different therapeutic schedules the 17-OHP levels ranged very widely from $2 \mathrm{ng} / \mathrm{ml}(6 \mathrm{nmol} / \mathrm{l})$ at 0800 or 1200 hours $^{4}$ to $33 \mathrm{ng} / \mathrm{ml}(100 \mathrm{nmol} / \mathrm{l})$ at 1200 hours $^{2}$, and raise two points. Firstly, in previous studies the time intervals between blood sampling for the circadian pattern of 17-OHP have been fairly long compared with our schedule. Moreover, there were no efforts to standardise the interval between drug intake and blood sampling. ${ }^{15}$ The importance of this fact is demonstrated in the figures which show that 17-OHP levels fell rapidly after the first dose in the morning. In some cases an interval of 90 minutes reduced the plasma level to half. It seems unlikely that a single 17-OHP value could provide information about the 24-hour suppression state.

Secondly, it is important to know whether the bigger or the smaller part of the total 24-hour glucocorticoid dose is given in the morning, and whether the drug is given twice or three times daily. Our observations explain why single $17-\mathrm{OHP}$ values did not correlate with either urinary pregnanetriol or with $17-\mathrm{KS}$ values. ${ }^{4}$ In order to demonstrate the pronounced difference in plasma 17-OHP between well-suppressed (day) and insufficiently-suppressed (night) periods, we divided the total integrated 17-OHP area into two fractions corresponding to 12-hour periods (1200-2400 and 2400-1200, Table 3). In all patients under treatment (except Cases 2 
and 6) the 17-OHP integrated area of the first period was distinctly smaller, and correlations between either fraction and urinary pregnanetriol were no longer significant. Hence, we question whether the 24-hour urinary pregnanetriol excretion which represented a mean of very unequal plasma 17-OHP periods, gave adequate information about the quality of corticosteroid therapy.

In conclusion, a single 17-OHP value is not a useful parameter for monitoring treatment in congenital adrenal hyperplasia; while standardisation of sampling time is not possible owing to the rapid changes in 17-OHP levels during the day.

We thank Mrs Arzberger for technical assistance.

\section{References}

1 Strott C A, Yoshimi T, Lipsett M B. Plasma progesterone and 17-hydroxyprogesterone in normal men and children with congenital adrenal hyperplasia. J Clin Invest 1969; 48: 930-9.

2 Grant D B, Dillon M J, Atherden S M, Levinsky R J. Congenital adrenal hyperplasia: renin and steroid values during treatment. Eur J Pediatr 1977; 126: 89-96.

3 Hughes I A, Winter J S D. The application of a serum 17-OH-progesterone radioimmunoassay to the diagnosis and management of congenital adrenal hyperplasia. J Pediatr 1976; 88: 766-73.

4 Hughes I A, Winter J S D. The relationships between serum concentrations of $17 \mathrm{OH}$-progesterone and other serum and urinary steroids in patients with congenital adrenal hyperplasia. J Clin Endocrinol Metab 1978; 46: 98-104.

5 Huseman C A, Varma M M, Blizzard R M, Johanson A. Treatment of congenital virilizing adrenal hyperplasia patients with single and multiple daily doses of prednisone. J Pediatr 1977; 90: 538-42.

6 Lippe B M, LaFranchi S H, Lavin N, Parlow A, Coyotupa J, Kaplan S A. Serum 17- $\alpha$-hydroxyprogesterone, progesterone, estradiol, and testosterone in the diagnosis and management of congenital adrena hyperplasia. J Pediatr 1974; 85: 782-7.

7 Parth K, Zimprich H, Swoboda W, Brunel R, Bohrn E. Congenital adrenal hyperplasia: simultaneous determination of plasma aldosterone and 17-hydroxyprogesterone. Acta Endocrinol (Kbh) 1978; 87: 148-57.

8 Pham-Huu-Trung $M T$, Gourmelen $M$, Girard $F$. Simultaneous assay of cortisol and 17- $\alpha$-hydroxyprogesterone in the plasma of patients with congenital adrenal hyperplasia. Acta Endocrinol (Kbh) 1973; 74: 316-30.

9 Schnakenburg K, Bidlingmaier F, Knorr D. 17- Hydroxyprogesteron, Testosteron, und Androstendion beim behandelten congenitalen adrenogenitalen Syndrom. Monatsschr Kinderheilkd 1978; 125 : 579-80.

10 Atherden S M, Barnes N D, Grant D B. Circadian variation in plasma 17-hydroxyprogesterone in patients with congenital adrenal hyperplasia. Arch Dis Child $1972 ; 47: 602-4$.

11 Korth-Schütz S, Virdis R, Saenger P, Chow D M, Levine L S, New M I. Serum androgens as a continuing index of adequacy of treatment of congenital adrenal hyperplasia. J Clin Endocrinol Metab 1978; 46: 452-8.

12 McKenna T J, Jennings A S, Liddle G W, Burr I M. Pregnenolone, 17-OH-pregnenolone, and testosterone in plasma of patients with congenital adrenal hyperplasia. $J$ Clin Endocrinol Metab 1976; 42: 918-25.

13 Solomon I L, Schoen E. Blood testosterone values in patients with congenital virilizing adrenal hyperplasia. J Clin Endocrinol Metab 1975; 40: 355-62.

14 Barnes N D, Atherden S M. Diagnosis of congenital adrenal hyperplasia by measurement of plasma 17hydroxyprogesterone. Arch Dis Child 1972; 47: 62-5.

15 Golden M P, Lippe B M, Kaplan S A, Lavin N, Slavin J. Management of congenital adrenal hyperplasia using serum dehydroepiandrosterone-sulfate and 17-hydroxyprogesterone concentrations. Pediatrics 1978; 61 : 867-71.

Correspondence to $\mathrm{Dr} \mathrm{H}$ Frisch, University Kinderklinik, A-1090 Wien IX, Währinger Gürtel 74-76, Austria.

Received 9 October 1979 